\title{
Ergenlerde, Aktif ve Pasif Sigara İçiminin Solunum Fonksiyon Testleri Üzerine Etkisi
}

\author{
The Effects of Active and Passive Smoking on Pulmonary Function in \\ Adolescent
}

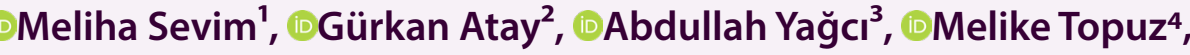 \\ Öznur Özdemir Arslan ${ }^{1}$
}

\author{
'Sağlık Bilimleri Üniversitesi, Ankara Eğitim ve Araştırma Hastanesi Çocuk Sağlığı ve Hastalıkları Kliniği , Ankara, Türkiye \\ ${ }^{2}$ Sağlık Bilimleri Üniversitesi, Ümraniye Eğitim ve Araştırma Hastanesi Çocuk Yoğun Bakım Kliniği, İstanbul, Türkiye \\ ${ }^{3}$ Birecik Devlet Hastanesi Çocuk Sağlığı ve Hastalıkları Kliniği, Şanlıurfa, Türkiye \\ ${ }^{4}$ Haymana Devlet Hastanesi, Çocuk Sağlığı ve Hastalıkları Kliniği , Ankara, Türkiye
}

\section{ÖZ}

Amaç: Bu çalışmanın amacı ergenlerde aktif ve pasif sigara içiminin solunum fonksiyonları üzerine etkisini belirlemektir.

Gereç ve yöntem: Bu çalışma, Haziran 2013-2015 tarihleri arasında, Ankara Eğitim ve Araştırma Hastanesi Çocuk Polikliniğine başvuran ergenler dahil edildi. Olguların ve ailelerinin sosyodemografik özelliklerini içeren anket formu ebeveynler tarafından dolduruldu. Olgular, aktif sigara içenler, pasif sigara içenler ve hiç içmeyenler olmak üzere üç gruba ayrıldı. Tüm olguların volumetrik spirometre ile solunum fonksiyon testleri yapıldı.

Bulgular: Çalışmaya alınan toplam 222 ergenin yaş aralığı 11-17 yaş (median:15 yaş) olup 102'si $(\% 45,9)$ erkek ve 120'si $(\% 54,1)$ kızdı. Aktif sigara içenler \%29,7 [n=66, median 16 yaş, 42 erkek (\%64) ve 24 kı (\%36)], pasif sigara içenler \%55,4 [ $n=123$, median 14 yaş, $52(\% 42,3)$ erkek ve $71 \mathrm{kIz}(\% 57,7)]$ ve hiç içmeyenler \%14,9 [n=33, median 14 yaş, 8 erkek $(\% 24,2)$ ve $25 \mathrm{kIz}(\% 75,8)]$ idi. Pasif sigara içenlerin FEF25-75 ve FEV1 değerleri aktif sigara içenlere göre farklı bulunmadı. Ancak, hiç içmeyenlerle karşılaştırıldığında anlamlı daha düşüktü (sırası ile $p=0,049 ; p=0,003$ ). Pasif sigara içen grubun FVC değerleri aktif sigara içen ve hiç sigara içmeyen gruba göre anlamlı olarak düşük saptandı (sırası ile, $p=0,020 ; p=0,010$ ).

Sonuç: Ergenlik döneminde sigara içme oranı yüksek saptandı $(\% 29,7)$. Pasif sigara içen grubun solunum fonksiyon testlerinin anlamlı düşük çıkması, sigaraya maruziyet oranının, maruziyet tipinden (aktif/pasif) daha etkili bir faktör olduğu kanısını ortaya koymuştur.

Anahtar Kelimeler: Ergen, sigara içimi, pasif sigara maruziyeti, solunum fonksiyon testleri

\section{ABSTRACT}

Purpose: To determine the effects of smoking and exposure type (active and passive) on pulmonary functions in adolescents.

Material and Method: Adolescents, who admitted to ages Ankara Training and Research Hospital's Pediatric Outpatient Clinics between June 2013 and 2015 were included in the study. The demographic parameters and sociodemographic characteristics of the cases and families were recorded in the questionnaired fulfilled by the parents. Three groups were constituted: Active smokers, passive smokers and nonsmokers. All of the cases' pulmonary function tests were determined with volumetric spirometry.

Results: A total of 222 adolescents, ages between 11-17 years [median 16 years,120 girls (54,1\%), 102 boys (45,9\%)] were included in the study. Active smokers were 29.7\% [n: 66, median 16 years old, 24 girls (36\%), 42 boys (64\%)], passive smokers were $55.4 \%$ [n:123, median 14 years old, 71 girls (57,7\%), 52 boys $(42,3 \%)$ and nonsmokers were $14,9 \%$ [n: 33, median 14 years old, 25 girls (75,8\%), 8 boys (24,2\%)]. Passive smokers' FEF25-75 and FEV1 values did not show a significant difference according to active smokers, however were significantly lower than nonsmokers (respectively; $p=0.049$ and $p=0.003$ ). Passive smokers also had significantly lower FVC values than active smokers and nonsmokers (respectively; $\mathrm{p}=0.020 ; \mathrm{p}=0.010$ ).

Conclusion: Prevelance of smoking habit is high in adolescents (29.7\%). Determining the respiratory function tests of passive smokers signicantly lower, suggest us that the amount of exposure is a more effective factor than type of exposure (active/passive).

Keywords;Adolescent, smoking, passive smoking, pulmonary function tests 


\section{GíRiş}

Pasif sigara içimi de aktif sigara içimi gibi ciddi ve ölümcül hastalıklara neden olabilen bir durumdur. Pasif içiciliğinin çocuklar ve bebeklerde özellikle solunum sistemi ve orta kulak hastalıklarına yakalanma riskini arttırdığı bildirilmiştir. Pasif içicilik, kısa ve az bile olsa zarar verebilmektedir ve bunun güvenli bir seviyesi de bulunmadığı kabul edilmektedir. Pasif içicilerin de aktif sigara içenler gibi erken ölüm ve artmış hastalıklar için büyük risk altında olduğu bilinmektedir (1).

Türkiye'de, 2012 yılından sonra tütün kullanımı oranları hem erkek hem de kadınlarda artış göstermiştir (2). Dünya Sağlık Örgütü (DSÖ) raporlarına göre, 2015 yılında ülkemizde 15 yaş ve üzeri olan erkeklerin \%40,2'si, kadınların \%12,4'ü, toplamda ise \%25,4 oranında olmak üzere 14.892.000 tütün kullanıcısı bulunmayd (3). Dünya genelinde 2016 yılında, 7,1 milyon kişinin tütün kullanımına bağlı hastalıklar sonucunda öldüğü bildirilmiştir. Bu ölümlerin 6,3 milyonunu aktif sigara içenler, 884 binini de pasif sigara içenler oluşturmuştur (4). Tüm dünyada çocukların \%40'ının evde sigaraya maruz kaldığı tahmin edilmektedir (5).

Türkiye'de 2017 yılına gelindiğinde ise, tütün kullanımında daha da artma olduğu görülmektedir. Tütün kullanımı oranları 2017'de erkeklerde \%42, kadınlarda \%16,9 ve toplamda \%29,5'e ulaşmıştır (6). Ülkemizde sigarayı bırakma oranının \%27,2'den 13,6'ya düştüğüne, bunun nedenleri arasında televizyon ya da radyoda sigara karşıtı uyarılar görmenin azalması ve sigara reklamlarının artması olarak işaret edilmiştir (2). Ülkemizde çocukların durumuna bakıldığında, ergenlerde 13-15 yaş arası erkek çocuklarda günlük tütün kullanım oranı \%23,2, kızlarda \%12,1, toplamda \%17,9’a yükseldiği görülmüştür (7).

Aktif sigara içen yetişkinlerde, solunum fonksiyon bozuklukları oluştuğu, birinci saniyedeki zorlu ekspirasyon volümü (FEV1), FEV1'in zorlu vital kapasite (FVC)'ye oranının (FEV1/FVC) ve zorlu ekspirasyonun orta yarısındaki ortalama akım hızı (FEF25-75)'nın daha düşük olduğu raporlanmıştır (8-13). Benzer şekilde ergenlerde de aktif ve pasif sigara içiminin FEV1, FEV1/FVC ve FEF25-75 değerlerini etkileyebileceği bildirilmiştir (12-16).

Birçok ülkede bu soruna karşı önemli adımlar atılmış ve pasif sigara içiminin önüne geçilmeye çalışılmıştır. Ülkemizde de bu önemli sorun dikkate alınmış ve önemli kararlar ve önlemler hayatımıza girmiştir. Buna rağmen pasif sigara içimi etkilerini sürdürmektedir $(2,6)$. Özellikle çocuklar ebeveynlerinin kullanımına bağlı olarak etkilenmektedirler.

$\mathrm{Bu}$ çalışmanın amacı; ergen yaş grubunda sigara içme sıklığını belirlemek ve sigaranın solunum fonksiyonları üzerindeki olumsuz etkilerini ortaya koymaktır.

\section{GEREÇ VE YÖNTEM}

Çalışmaya, Haziran 2013-2015 tarihleri arasında Ankara Eğitim ve Araştırma Hastanesi Çocuk Polikliniklerine başvuran, 11-17 yaş aralığındaki 222 ergen dahil edildi. Ergenlerden ve ebeveynlerinden yazılı onam alındı. Çalışmaya katılmayı kabul eden ebeveynlere, 19 sorudan oluşan seçmeli anket formu verildi. Çalışmaya dahil edilen ergenlerin sosyodemografik özellikleri, ebeveynlerin okur-yazar durumu ve sigara içimi, anket formundaki verilerden elde edildi. Fizik muayenede enfeksiyonu veya öyküsünde astım, bronşit ve kronik hastalığı bulunanlar çalışmaya dahil edilmedi.

Olgular sigara içme durumlarına göre üç gruba ayrıldı:

1. grup (sigara içen): Günde en az bir adet sigara kullanan olgular. Bu grupta ebeveynde sigara kullanımı aranmadı.

2. grup (pasif sigara içen): Hiç sigara kullanmamış, ebeveynlerden en az bir tanesi günlük bir adet ve üzeri sigara kullanan olgular.

3. grup (sigara maruziyeti olmayan): Hiç sigara kullanmamış ve ebeveynlerinde sigara kullanımı olmayan olgular

Her üç gruba solunum fonksiyon testi yapıldı. Ölçüm kuru portabl flow volümetrik spirometre cihazı kullanılarak gerçekleştirildi. Çocuklara testin uygulanışı hakkında bilgi verildi. Solunum fonksiyon testi yapma sertifikası olan hemşire eşliğinde ölçümler yapıldı. En az üç deneme yapılarak aygıtın seçtiği en iyi değer çalışmaya alındı. Her üç gruptaki çocukların, zorlu vital kapasite (FVC), birinci saniyedeki zorlu ekspirasyon volümü (FEV1), FEV1/FVC ve zorlu ekspirasyonun orta yarısındaki ortalama akım hızı (FEF25-75) parametreleri ölçüldü. Yüzde değerler spirometre verileriyle otomatik olarak hesaplandı. "İnsan” öğesinin içinde bulunduğu bu çalışma, Helsinki Deklarasyonu prensiplerine uygun olarak yapılmıştır. Etik kurul izni: (18/01/2013) 513:4295

\section{İstatistiksel Analiz}

Verilerin analizi IBM SPSS (Stastistical Package For the Social Sciences) 20 paket programında yapıldı. Sürekli ve kesikli sayısal değişkenlerin dağılımının normale yakın olup olmadığı Kolmogorov Smirnov testiyle araştırıldı. Normal dağılıma uyan değişkenler (yaş) ortalama \pm standart sapma (SD), uymayanlar ortanca [minumum, maximum (min-max)], kategorik değişkenler ise olgu sayısı ve "\%" biçiminde gösterildi. Sonuçlar \%95 güven aralığında, anlamlılık $\mathrm{p}<0,05$ düzeyinde değerlendirildi.

Sürekli verilerin normal dağılıma uygunluğu ShapiroWilk testi ile incelendi. Normal dağılıma uyan verilerin üç grupta karşılaştırılmasında Tek Yönlü Varyans Analizi (ANOVA) kullanıldı. Gruplar arasındaki farkın hangi gruplardan kaynaklandığı Tukey test ile incelendi. 
Normal dağılıma uymayan verilerin üç grupta karşılaştırılmasında Kruskal Wallis Varyans Analizi kullanıldı. Gruplar arasındaki farkın hangi gruplardan kaynaklandığı Kruskal Wallis çoklu karşılaştırma testi ile incelendi. Nominal değişkenlerin grup karşılaştırmalarında (çapraz tablolarda) Ki-Kare test kullanıldı.

Değerlendirmelerde istatistiksel anlamlılık sınırı olarak $\mathrm{p}<0,05$ kabul edildi.

\section{BULGULAR}

Çalışmaya dahil edilen 11-17 yaş arası $102(\% 45,9)$ erkek ve $120(\% 54,1)$ kız olgunun ortanca yaşları 15 yaş olarak bulundu. Cinsiyetlere göre istatistiksel fark saptanmadı $(p=0,105)$. Olguların sosyodemografik özellikleri incelendiğinde aktif sigara içen grubun ortanca yaşı 16 (12-17) yıl olarak bulundu; aktif sigara içen grubun ortanca yaşı, pasif sigara içen ve içmeyen gruba göre istatistiksel olarak anlamlı daha büyük bulundu (sırasıyla $\mathrm{p}<0,001 ;<0,001$ ) (Tablo 1). Aktif sigara içen grupta erkek cinsiyet sıklığı, pasif sigara içen ve içmeyen gruba göre istatistiksel olarak anlamlı büyük bulundu (sırasıyla, $\mathrm{p}<0,01 ;<0,001)$.

Aktif sigara içen grupta, sigara içme süreleri incelendiğinde olguların \%21,2'si bir yıldan az, \%56,1'i bir-üç yıl, \%15,2'si dört-altı yıl, \%7,6'sının altı yıldan fazla süredir sigara içtiği saptandı. Sigara içme sürelerine ve miktarlarına göre FEV1, FVC, FEV1/FVC, FEF25-75ve PEF değerleri ayrı ayrı karşılaştırıldığında anlamlı fark bulunmadı ( $p>0,05)$. Günde 10 adet altında içenlerin oranı \%69,7 olarak bulundu. Ebeveynlerin sigara içme oranı değerlendirildiğinde kadınlarda \%36,5 ( $n=81)$, erkeklerde \%69,4 ( $n=154)$, olarak bulundu.

Pasif sigara içimi olan grubun FVC parametrelerinin ortalaması ( \pm SD) $100,1 \pm 13,1$ olup aktif sigara içen ve içmeyen gruba göre anlamlı olarak düşük saptandı (sırası ile, $p=0,020 ; 0,010$ ) (Tablo 2). Pasif sigara içimi olan grubun FEV1 ve FEF25-75 parametrelerinin ortalaması ( \pm SD) $105,5 \pm 15,4$ ve $104,9 \pm 28,2$ olarak bulundu. Bu değerler sigara içmeyen gruba göre anlamlı düzeyde düşük saptandı (sırasıyla, p=0,003; 0,049).

Annelerin \%53,1'i ( $n=43)$, babaların \%48,7'si $(n=75) 10$ paket/yıl ve üstünde sigara içmektedirler. Aktif sigara içen ergenlerde babası 10 paket/yıl ve üstünde sigara içme oranı \%52,5 $(n=21)$ iken pasif sigara içen ergenlerde bu oran $\% 47,4(n=54)$ olarak bulundu $(p=0,576)$.

Yine aktif sigara içen ergenlerde annesi 10 paket/yıl ve üstünde içenlerin oranı $\% 57,7(n=15)$ iken, pasif sigara içen ergenlerde bu oran \%50,9 $(n=28)$ olarak bulundu $(p=0,568)$. Aktif sigara içen ve pasif sigara içen ergenlerin anne ve babalarının 10 paket/yıl ve üstünde sigara içme oranları arasında fark saptanmadı $(p>0,05)$.

Tablo 1. Çalışma grubunun sosyodemografik özellikleri

\begin{tabular}{|c|c|c|c|c|c|}
\hline Özellikler & $\begin{array}{c}\text { Grup } 1 \\
\text { Sigara içen } \\
n=66\end{array}$ & $\begin{array}{c}\text { Grup } 2 \\
\text { Pasif sigara içen } \\
n=123\end{array}$ & $\begin{array}{c}\text { Grup } 3 \\
\text { Sigara içmeyen } \\
n=33\end{array}$ & $\begin{array}{l}\text { Toplam } \\
n=222\end{array}$ & $\mathbf{p}$ \\
\hline $\begin{array}{l}\text { Ortanca yaş } \\
\text { (en küçük-en büyük) }\end{array}$ & $16(12-17)$ & $14(11-17)$ & $14(12-17)$ & $15(11-17)$ & 0,001 \\
\hline \multicolumn{6}{|l|}{ Cinsiyet, n (\%) } \\
\hline $\begin{array}{l}\text { Erkek } \\
\mathrm{K} \mathrm{Iz}\end{array}$ & $\begin{array}{l}42(63,6) \\
24(36,4)\end{array}$ & $\begin{array}{l}52(42,3) \\
71(57,7)\end{array}$ & $\begin{array}{c}8(24,2) \\
25(75,8)\end{array}$ & $\begin{array}{l}102(45,9) \\
120(54,1)\end{array}$ & $<0,000$ \\
\hline $\begin{array}{l}\text { Anne ortanca yaşı } \\
\text { (en küçük-en büyük) }\end{array}$ & $42(30-64)$ & $39(27-52)$ & $38(30-60)$ & $39(27-64)$ & 0,003 \\
\hline $\begin{array}{l}\text { Baba ortanca yaşı } \\
\text { (en küçük-en büyük) }\end{array}$ & $44(30-77)$ & $42(32-60)$ & $44(34-61)$ & $43(30-77)$ & 0,014 \\
\hline \multicolumn{6}{|l|}{ Anne eğitimi n (\%) } \\
\hline Yok & $16(24,2)$ & $49(39,8)$ & $15(45,5)$ & $80(36,0)$ & \\
\hline Orta & $35(53,0)$ & $59(48,0)$ & $12(36,4)$ & $106(47,7)$ & 0,086 \\
\hline Lise ve üzeri & $15(22,7)$ & $15(12,2)$ & $6(18,2)$ & $36(16,3)$ & \\
\hline \multicolumn{6}{|l|}{ Baba eğitimi n (\%) } \\
\hline Yok & $41(62,1)$ & $66(53,6)$ & $13(39,4)$ & $120(54,0)$ & \\
\hline Orta & $11(16,7)$ & $35(28,5)$ & $9(27,3)$ & $55(24,8)$ & 0,110 \\
\hline Lise ve üzeri & $14(21,2)$ & $22(17,9)$ & $11(33,3)$ & $47(21,2)$ & \\
\hline
\end{tabular}

\begin{tabular}{lccccc} 
Tablo 2: Çalışma grubunun solunum fonksiyon testlerinin değerlendirilmesi & (ortalama \pm SD) \\
Özellikler & $\begin{array}{c}\text { Grup 1 } \\
\text { Sigara içen } \\
\mathbf{n = 6 6}\end{array}$ & $\begin{array}{c}\text { Grup 2 } \\
\text { Pasif sigara içen } \\
\mathbf{n = 1 2 3}\end{array}$ & $\begin{array}{c}\text { Grup 3 } \\
\text { Sigara içmeyen } \\
\mathbf{n = 3 3}\end{array}$ & $\begin{array}{c}\text { Toplam } \\
\mathbf{n = 2 2 2}\end{array}$ & $\mathbf{p}$ \\
\hline FVC & $105,7 \pm 15,7$ & $100,1 \pm 13,1$ & $107,9 \pm 12,9$ & $102,9 \pm 13,9$ & 0,002 \\
FEV1 & $110,5 \pm 17,1$ & $105,5 \pm 15,4$ & $115,9 \pm 15,9$ & $108,5 \pm 16,4$ & 0,002 \\
FEV1/FVC & $102,7 \pm 10,6$ & $103,4 \pm 8,2$ & $105 \pm 8,2$ & $103,4 \pm 8,9$ & 0,483 \\
FEF25-75 & $111,9 \pm 34,3$ & $104,9 \pm 28,2$ & $118,8 \pm 26,7$ & $109,1 \pm 30,2$ & 0,042 \\
PEF & $101,6 \pm 19,4$ & $97,6 \pm 15,8$ & $101,8 \pm 16,9$ & $.99,4 \pm 17,2$ & 0,211
\end{tabular}


Anne ve babaların sigara içme süreleri 5 yıldan az olanlarla 5 yıldan fazla olanların FEV1, FVC, FEV1/FVC, FEF25-75 ve PEF değerleri karşılaştırılmış olup anlamlı fark bulunmadı ( $p>0,05)$. Yine günlük 1 paketten az ve 1 paketten fazla sigara içen anne ve babaların çocuklarının FEV1, FVC, FEV1/FVC, FEF25-75 ve PEF değerleri karşılaştırıldığında anlamlı fark saptanmadı ( $p>0,05)$.

\section{TARTIŞMA}

Sigara kullanıcıların çoğu 25 yaşından önce, bunların çoğunluğu da ergenlik döneminde sigaraya başlamaktadır (17). Türkiye'de farklı illerde yapılan çeşitli çalışmalarda 18 yaş altı sigara içme sıklığının $\% 9,5$ ile \%41,2 arasında olduğu gösterilmiştir $(17,18)$. Çalışmamıza katılan ergenlerde aktif sigara içme sıklığı \%29,7 ve aktif sigara içenlerin yaş ortalaması 16'dır. DSÖ, 2008 yılında yayınlamış olduğu küresel tütün salgını raporunda, gelişmekte olan ülkelerde ergenlerde aktif sigara içme sıklığının hızla artmakta olduğunu ifade etmiştir (19). Sağlık Bakanlığı Sağlık İstatistikleri Yıllığı 2018 verilerine göre de 15-24 yaş aralığında her gün tütün kullanan birey sayısı 2012 yılında \%14,3 iken 2016 yılında bu oran \%18,1'e yükselmiştir (20). Türkiye İstatistik Kurumunun en son 2012'de yayımlanan araştırmasında, ülkemizde 15 yaş ve üzeri bireylerin \%27'si her gün veya ara sıra tütün kullanmaktadır. Cinsiyete göre değerlendirildiğinde bu oran erkeklerde \%41,4, kadınlarda \%13,1'dir (21).

Çalışmamızda ebeveynlerin \%52'sinin sigara içtiği ve içme oranının erkeklerde \%69,4, kadınlarda ise \%36,5 olduğu görülmüştür. Ülkemizde yapılan çeşitli çalışmalara göre bu oranlar farklılık göstermektedir. Özyurt'un bir ilkokulda okuyan çocuklara yönelik çalışmasında, çocukların büyük çoğunluğunun evinde en az bir kişi sigara içicisi olup çocuklar sigara dumanına maruz kaldığı belirtilmektedir (22). Küçük ve arkadaşlarının Yozgat'ta 873 hasta üzerine yaptığı bir çalışmada, çocukların \%33,6'sının evde sigara dumanına maruz kaldığı ve maruz kalan çocukların da \%38,9'unda solunum sistemi hastalığı görüldüğü belirtilmiştir (23). 2016 yılında Antalya'da 0-11 yaş çocukların evde sigara dumanından pasif etkilenmelerini araştıran başka bir çalışmada annelerin \%31'inin, babaların \%45,1'inin sigara içtiği ve sigara içen annelerin \%80'inin, babaların ise $\% 76,5^{\prime}$ inin evde de sigara içtiği tespit edilmiştir (24). Nazlıer'in alt solunum enfeksiyonu nedeniyle hastaneye başvuran 5 yaş altı çocuklarda pasif içiciliğin etkisinin araştırılmasına yönelik doktora tezinde annelerin \%30,6'sının babaların ise \%82,9'unun sigara içtiği ve sigara içen annelerin \%67,9'unun, babaların ise \%69'unun çocukların yanında sigara içtiği görüldüğü belirtilmiştir (25).

Literatürde erişkinlerde sigaranın solunum fonksiyonları üzerine etkisini araştıran birçok çalışma olmasına rağmen ergenlerde yapılmış çalışma sayısı kısıtlıdır. 10-18 yaş arası 10.010 olgu ile yapmış bir çalışmada aktif sigara içenlerde FEV1 değerinin sigara içmeyenlere göre anlamlı olarak düştüğü tespit edilmiştir (26). Bird ve Orzco'nun 13-15 yaş arası 300 öğrenci ile yaptığı bir çalışmada da aktif sigara içenlerin FEV1, FEV1/FVC ve FEF25-75 değerleri sigara içmeyenlere göre anlamlı düşük bulunmuştur (8). Fakat Ghanem ve Hage'nin 18-24 yaş arası üniversite öğrencilerinde aktif ve pasif sigara içiminin etkilerini araştırdığı çalışmada sigara içen ve içmeyenlerin FEV1 düzeyleri arasında anlamlı fark bulunamamıştır (27). Benzer şekilde Jawed S ve arkadaşlarının 19-25 yaş arasındaki gençlerde yapmış olduğu başka bir çalışmada da aktif sigara içen ve içmeyenler arasında FEV1 değerlerinde anlamlı fark bulunamamıştır (28). Aynı çalışmada günde içilen sigara sayısı ile FEV1 ilişkisi değerlendirildiğinde günde 10 ve üzeri sigara içenlerin daha az sigara içenlere göre FEV1 değerleri anlamlı düşük bulunmuştur (28). Çalışmamızda aktif sigara içenlerin FEV1 değerleri, pasif sigara içenler ve hiç içmeyenlerle karşılaştırıldığında istatistiksel olarak anlamlı fark bulunmamış olsa da aktif sigara içenlerin FEV1 değerleri, sigara içmeyenlere göre düşük bulunmuştur. Bunun nedeni sigara içen ergenlerin günlük sigara miktarının ve sigara içme süresinin düşük olması olabilir.

Guerra ve arkadaşları prospektif olarak aktif ve pasif sigara maruziyetinin akciğer fonksiyonuna etkisini değerlendirdiği bir çalışmada 11, 16 ve 22 yaşlarındaki bireylerin FEV1/FVC değerlerini kıyaslamıştır. Çalışmada hem aktif sigara içenlerde hem de pasif sigara içenlerde aynı yaşlardaki içmeyenlerle FEV1/FVC değerleri kıyaslandığında aralarında fark bulunmamıştır. Halbuki aynı çalışmada 11 ve 26 yaşlarındaki FEV1/FVC oranları karşılaştırıldığında aktif ve pasif sigara içenlerde FEV1/ FVC oranlarında anlamlı düşüş görülmüştür (29). Thacher ve arkadaşlarının 16 yaşındaki 2295 ergenle yaptığı başka bir çalışmada aktif sigara içenler ile sigara maruziyeti olmayanların FEV1/FVC oranları kıyaslanmış olup aktif sigara içenlerde anlamlı düşük bulunmuştur (30). Çalışmamızda aktif sigara içen, pasif sigara içen ve sigara içmeyenler arasında yapılan karşılaştırmada FEV1/ FVC oranlarında istatistiki olarak anlamlı fark görülmese de sigara içenlerde FEV1/FVC oranı ortalaması düşük bulunmuştur.

Çalışmamızda pasif sigara içenlerin sigara içmeyenlere göre FEV1 değerleri daha düşük saptanmış olup Plata ve arkadaşlarının (31) Meksika'da 8-17 yaş arası 1632 erkek ve 1555 kız olgu ile yapmış olduğu bir çalışmada da çalışmamıza benzer şekilde pasif sigara içenlerin FEV1 ve FVC değerlerinin sigara içmeyenlere göre anlamlı olarak düştüğü tespit edilmiştir. Yine Merghani ve Saeed'in (32) yaptığı bir çalışmada da 9-14 yaş aralığında 135 erkek öğrenci değerlendirilmiş ve pasif sigara maruziyeti olan 69 çocuğun sigara maruziyeti olmayanlara göre ortalama FVC değerinin \%8, FEV1 değerinin \%7 düşük olduğu 
gösterilmiştir. Uysal ve arkadaşlarının (33) yaptığı bir çalışmada ise pasif sigara içici olan grupla içici olmayan grup karşılaştırılmış olup solunumsal parametreler arasında anlamlı bir fark bulunamamıştır.

Pasif sigara dumanına maruz kalan ergenlerin FEV1 ve FEF25-75 değerlerinin sigara maruziyeti olmayanlara göre düşük olması erken dönemden itibaren pasif sigara maruziyetinin etkin olduğunu göstermektedir. Milanzi ve arkadaşlarının 12 ve 16 yaşlarındaki 552 ergenle yaptığı bir çalışmada çocukluk çağı pasif sigaraya maruz kalma ihtimali yüksek olanlarda düşük olanlara göre kıyaslandığında 12 ve 16 yaşları arasındaki yıllık FEV1 büyümesinde azalma olduğu görülmüştür (34).

Çalışmamızda bazı kısıtılıklar bulunmaktadır. Adolesan dönemde sigara içen çocukların, ailelerinden çekinerek, bu konuda doğru bilgi vermeyebileceği gibi sigara içen anne ve babaların da suçluluk duygusuyla doğru söylemeyebilirler. Çalışmamızda çocukların sigara kullanımı ebeveyn ve ergenlerin beyanına göre öğrenilmiş olup ergenlere ve ailelere objektif olarak nikotin metaboliti bakılamamıştır.

\section{SONUC}

Sigara içme sıklığının ergenler ve erişkinlerde yükseldiği tespit edilmiştir. Pasif sigara içicilerin solunum fonksiyon testinin aktif sigara içenlere göre daha düşük çıkması maruziyet oranının, maruziyet tipinden (aktif/pasif) daha etkili bir faktör olduğu kanısını desteklemiştir. Genel olarak toplumda tütün kullanımının azaltılmasına yönelik özel olarak da pasif sigara içiciliği maruziyetinin ve oranının azaltılmasına yönelik, projelerin desteklenmesi ile ergen sağlığı korunabilir. Bununla birlikte, toplum, aile ve bireylere yönelik eğitim ve bilinçlendirme faaliyetleri ile daha etkin önlemlerin alınması gerektiği aşikardır.

Daha geniş ve kapsamlı çalışmalarla, ergenlerde aktif ve pasif sigara içimi prevalansının ve zararlı etkilerinin ortaya konularak bilgilendirme ve önleme çalışmalarının yapılması gerekmektedir.

\section{ETIK BEYANLAR}

Etik Kurul Onayı: Araştırma için etik kurul onayı alınmıştır (18/01/2013) 513:4295.

Aydınlatılmış Onam: Çalışma retrospektif olarak dizayn edildiği için hastalardan aydınlatılmış onam alınmamıştır.

Hakem Değerlendirme Süreci: Harici çift kör hakem değerlendirmesi.

Çıkar Çatışması Durumu:Yazarlar bu çalışmada herhangi bir çıkara dayalı ilişki olmadığını beyan etmişlerdir.

Finansal Destek: Yazarlar bu çalışmada finansal destek almadıklarını beyan etmiş̧lerdir.
Yazar Katkıları: Yazarların tümü; makalenin tasarımına, yürütülmesine, analizine katıldığını ve son sürümünü onayladıklarını beyan etmişlerdir.

\section{KAYNAKLAR}

1. WHO report on the global tobacco epidemic, 2019: Offer help to quit tobacco use. İnternet adresi: https://apps.who.int/iris/ bitstream/handle/10665/326043/9789241516204-eng.pdf?ua=1

2. 7 Kasım 2019 TBMM Tütün Kontrolü İstişare Toplantısı. Türk Toraks Derneği (TTD) Tütün Kontrolü Çalışma Grubu Raporu. İnternet adresi: https://www.toraks.org.tr/subNews. aspx?sub $=189$ \& notice $=5477$

3. WHO global report on trends in tobacco smoking 2000-2025 First edition. Internet adresi: https://apps.who.int/iris/bitstream/ handle/10665/156262/9789241564922 eng.pdf;jsessionid= 71D0021A555432620E90EDCB0714E827? sequence=1

4. 20 Temmuz 2018 Sigara ve Akciğer Kanseri ilișkisi/Türk Toraks Derneği Halk Sağlığı İnternet adresi: https://www.toraks.org.tr/ halk/News.aspx?detail $=4768$

5. Pugmire J, Sweeting $\mathrm{H}$, Moore L. Environmental tobacco smoke exposure among infants, children and young people: now is no time to relax. Arch Dis. Child. 2017;102:117-118.

6. WHO report on the global tobacco epidemic, 2019: appendixes X, XI and XII. Table X.1: Age-standardized prevalence estimates for tobacco use, 2017. Internet adresi: https://www.who.int/ tobacco/global_report/en/

7. İnternet adresi: https://www.who.int/tobacco/global_report/en/ appendixes X, XI and XII. Table XI.3: Youth surveys tobacco use and smoking.)

8. Bird Y, Orozco HS. Pulmonary effects of active smoking and secondhand smoke exposure among adolescent students in Juarez, Mexico. Int J Chron Obstruct Pulmon. Dis. 2016;11:14591467.

9. James $A L$, Palmer LJ, Kicic $E$, et al. Decline in lung function in the Busselton Health Study: the effects of asthma and cigarette smoking. Am J Respir Crit Care Med. 2005;171:109-114.

10. Tager IB. The effects of second-hand and direct exposure to tobacco smoke on asthma and lung function in adolescence. PaediatrRespirRev. 2008;9(1):29-37.

11. Simmons MS, Connett JE, Nides MA, et al. Smoking reduction and the rate of decline in FEV(1): results from the Lung Health Study. EurRespir J. 2005;25:1011-1017.

12. Orton $\mathrm{S}$, Jones LL, Cooper $\mathrm{S}$, et al. Predictors of children's second hand smoke exposure at home: a systematic review and narrative synthesis of the evidence. PLoSOne. 2014;9(11):e112690.

13. Corbo GM, Agabiti N, Forastiere $\mathrm{F}$, et al. Lungfunction in children and adolescents with occasional exposure to environmental tobacco smoke. Am J RespirCritCareMed. 1996;154:695-700.

14. Gibbs K, Collaco JM, McGrath-Morrow SA. Impact of tobacco smoke and nicotine exposure on lung development. Chest. 2015 Oct 22.

15. Cook DG, Strachan DP, Carey IM. Parental smoking and spirometric indices in children. Thorax. 1998;53:884-893.

16. Burr ML, Anderson HR, Austin JB, et al. Respiratory symptoms and home environment in children: a national survey. Thorax. 1999;54:376.

17. Akgül S, Kutluk T. Çocuk ve ergenlerde tütün kontrolü. Sürekli Tıp Eğitimi Dergisi 2015;24:1-5.

18. Doğan DG, Ulukol B. Ergenlerin sigara içmesini etkileyen faktörler ve sigara karşıtı iki eğitim modelinin etkinliği. Turgut Özal Tıp Merkezi Dergisi 2010;17(3):179-185.

19. DSÖ Küresel tütün Salgını Raporu 2008. http://whqlibdoc.who. int/publications/2008/9789241596282_tur.pdf

20. Sağlık bakanlığı sağlık istatistikleri yıllığı 2018 https://dosyasb. saglik.gov.tr/Eklenti/36134,siy2018trpdf.pdf?0

21. Küresel yetişkin Tütün araştırması, 2012, TUiK.http:// www.tuik.gov.tr/PreHaberBultenleri.do;jessionid= 6JnyYzLQFTDpBTLs64JXh0zC4Q1pnOrPqBvKncthn3vgZJ0fpB8n! 1473197797 ? id=13142

22. Özyurt BC. Manisa'da kırsal bir bölgedeki ilkokul çocuklarında pasif sigara içicilik maruziyetinin değerlendirilmesi. Türk Toraks Der. 2009;10:155-161 
23. Küçük Ö, Göçmen Y, Biçer S. Yozgat'ta yaşayan çocuklarda pasif içiciliğin solunum sistemi hastalıkları üzerine etkisi. JoppDerg 2012;4(3):124-129.

24. Akçay $D$, Ozcebe $H$. Çocukların evde sigara dumanından pasif etkilenme durumlarının incelenmesi Zeynep Kamil Tıp Bülten 2018;49(3):229-36.

25. Nazlıer K. Bir Eğitim araştırma hastanesinde alt solunum yolu infeksiyonu nedeniyle başvuran beş yaş altı çocuklarda pasif içiciliğin etkisinin araştırılması (Doktora Tezi). Fırat Üniversitesi. 2014.

26. Gold DR, et al. Effects of cigarette smoking on lung function in adolescent boys and girls. NEngl. J. Med. 335.13 (1996): 931-937.

27. Ghanem E, Hage R. Behavior of lung health parameters among smokers and secondhand smokers. J.Environ. PublicHealth. 2018;htttps://doi.org/10.1155/2018/5217675.

28. Jawed, Shireen, SaimaEjaz, and Rehana Rehman. Influence of smoking on lung functions in young adults. J. Pak. Med. Assoc.62.8 (2012): 772.

29. Guerra S, Stern DA, Zhou M, Sherrill D. L, et al. Combined effects of parental and active smoking on early lung function deficits: a prospective study from birth to age 26 years. Thorax 2013;68:1021-1028.

30. Thacher JD, Schultz ES, Hallberg J, et al. Tobacco smoke exposure in early life and adolescence in relation to lung function. Eur. Respir. J. 2018;51:1702111.

31. Plata RF, Martinez RR, Briseno DM, Sancho CG, Padilla RP. Effect of passive smoking on the growth of Pulmonary function and respiratory symptoms in school children. Rev. Inves. Clin. 2016;68:119-27.

32. Merghani TH, Saeed AM.The relationship between regular second-hand smoke exposure at home and indictors of lung function in healthy school boys in Khartoum. Tob. Control. 2013 ;22(5):315-8. doi: 10.1136/tobaccocontrol-2011-050169.

33. Uysal H, Bayraktar D, Gökbel H, Ergene N. Pasif sigara içicisi çocuklarda solunum fonksiyon testleri. Genel Tıp Dergisi $1997 ; 7(2)$.

34. Milanzi EB, Koppelman GH, Smit HA, et al. Timing of secondhand smoke, pet, dampness or mould exposure and lung function in adolescence. Thorax 2020;75:153-163. 